\title{
Recursos Financeiros, Materiais e Humanos para o Desenvolvimento de Atletas Olímpicos Brasileiros de Saltos Ornamentais
}

http://dx.doi.org/10.11606/1807-5509202000020271

\author{
Márcia Cristina Custódio FERREIRA* \\ Luiz Carlos Couto de Albuquerque MORAES** \\ Cleiton Pereira REIS** \\ Varley Teoldo COSTA ${ }^{* *}$
}

*Instituto Federal Goiano, Goiania, GO, Brasil.

**Universidade Federal de Minas Gerais, Belo Horizonte, MG, Brasil.

\section{Resumo}

0 objetivo do estudo foi analisar os recursos financeiros, materiais e humanos, através da percepção dos treinadores de saltos ornamentais, para o desenvolvimento de atletas olímpicos brasileiros. A amostra foi composta por seis treinadores de saltos ornamentais, com média de idade de 49,5 $\pm 14,1$ anos, que já treinaram atletas olimpicos no país. Foram realizadas entrevistas semiestruturadas com os treinadores. 0 conteúdo das entrevistas foi transcrito literalmente, e depois analisado através de miniunidades (MUs). As MUs foram organizadas em três categorias. Tanto o conteúdo das entrevistas quanto a categorização das MUs passaram pelo crivo de experts. Quanto aos recursos financeiros, os treinadores relataram que possuem baixos salários e uma elevada jornada de trabalho. Três entrevistados ressaltaram a falta ou precariedade dos recursos materiais. A maior parte dos treinadores não possui uma equipe multidisciplinar para desenvolver os atletas, sendo a carência de recursos humanos o fator que mais atrapalha a atividade laboral desses profissionais. Conclui-se que os saltos ornamentais no Brasil apresentam uma estrutura deficitária referente aos recursos financeiros, materiais e humanos para 0 desenvolvimento de atletas olímpicos.

Palavras-chave: Educação Física e Treinamento; Esportes Aquáticos; Infraestrutura; Esporte de Elevado Rendimento.

\section{Introdução}

A expert performance, aérea de investigação que estuda indivíduos considerados experts ${ }^{1,2}$, visa compreender como ocorre o desenvolvimento de experts em determinada área ou tarefa ${ }^{1-3}$. Considerase que a prática deliberada é um fator fundamental para o atleta alcançar um elevado nível de excelência esportiva ${ }^{1-4}$.

A prática deliberada é definida como prática constante e de longa duração ${ }^{5}$ que requer monitoramento e planejamento ${ }^{3,4}$. A prática deliberada está inserida em um contexto de treinamento de excelência, o que requer investimentos com a manutenção de treinadores, equipamentos, competiçōes, profissionais multidisciplinares, entre outros fatores estruturais objetivando garantir um elevado nível de desempenho dos atletas ${ }^{2,6,7}$. Sendo assim, de acordo com a literatura ${ }^{2,3,5-7}$ um atleta de saltos ornamentais precisa de recursos adequados para atingir um patamar de atleta olímpico.

Um estudo clássico na área de expertperformance, com treinadores canadenses de ginástica artística, buscou identificar o conhecimento de treinadores experts a respeito do desenvolvimento de atletas visando à excelência esportiva, e, a partir deste estudo, foi possível estabelecer um "modelo do

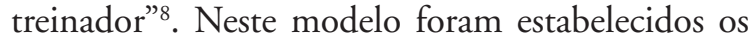
aspectos que determinam a intervenção do treinador para a preparação de atletas, como: competição, treinamento, organização, características pessoais do treinador, características pessoais do atleta, nível de desenvolvimento do atleta e fatores contextuais. Dentro do contexto de treinamento, considerase que recursos financeiros, materiais e humanos são os pilares para a formação esportiva ${ }^{6,7,9}$. Os 
recursos financeiros referem-se aos fatores que envolvem o salário e as condições de trabalho do treinador; os recursos materiais estão relacionados aos equipamentos necessários para o desenvolvimento dos atletas; e os recursos humanos aos profissionais que fazem parte da equipe multidisciplinar, como auxiliares técnicos, fisioterapeutas, psicólogos do esporte, entre outros ${ }^{8,9}$.

No que tange o desenvolvimento de jovens atletas, evidências apontam que os países que possuem um maior sucesso em competiçôes internacionais, como jogos olímpicos, são aqueles que possuem políticas públicas eficientes voltadas para o esporte ${ }^{10}$. Neste contexto, o apoio governamental e de patrocinadores, no sentido de ceder recursos adequados para o treinamento dos atletas, é um fator essencial para que um país consiga desenvolver atletas experts em uma determinada modalidade esportiva ${ }^{6,711}$.

Em algumas modalidades esportivas, como os saltos ornamentais e a ginástica artística, os recursos materiais são extremamente específicos, o que pode prejudicar o desenvolvimento de um atleta que não tenha equipamentos adequados para treinar ${ }^{12}$. Na literatura encontram-se estudos que investigaram os recursos de uma determinada modalidade, como por exemplo, no trabalho de FERREIRA et al. ${ }^{6}$, que investigaram o desenvolvimento de nadadores olímpicos brasileiros; Schiavon e Paes $^{12}$, Nunomura e Oliveira ${ }^{13}$ que analisaram a infraestrutura disponível aos atletas da seleção brasileira olímpica feminina de ginástica artística; ReIs et al. ${ }^{7}$ que verificaram os recursos que atletas masculinos de basquetebol de categoria de base de Minas Gerais tinham à disposição; Lima et al. ${ }^{14}$, que analisaram o contexto de desenvolvimento de atletas de ginástica artística do estado de São Paulo, e Silva Filho et al. ${ }^{15}$ que investigaram se existe um sistema de desenvolvimento de atletas talentosos na natação e no judô. Um ponto em comum apontado por esses estudos está relacionado à importância dos recursos financeiros, materiais e humanos adequados para o desenvolvimento de atletas em diferentes modalidades rumo a um desempenho de excelência. Porém, não foi encontrado na literatura estudos que analisaram os recursos que atletas de saltos ornamentais têm à disposição para treinamentos e competições, principalmente para aqueles que pretendem atingir o patamar de atleta olímpico.

Os saltos ornamentais é uma modalidade aquática vinculada à Federação Internacional Aquática ${ }^{16}$. É considerada uma modalidade olímpica desde $1904^{17}$. Embora seja considerado um esporte aquático, o atleta precisa desenvolver elementos fora da piscina para que seu desempenho acrobático aéreo e finalização do salto na água possam ser maximizados. Grande parte dos elementos que são treinados fora da água se assemelham com os movimentos da ginástica artística, tais como rolamentos, paradas de mão e mortais. Além disso, existem equipamentos utilizados para o desenvolvimento dos atletas de saltos ornamentais que são os mesmos utilizados na ginastica olímpica (cama elástica, colchões, espaldares, piscina de espuma). Apesar de utilizar equipamentos e movimentos de outras modalidades, há uma especificidade acrobática nos saltos ornamentais em função das regras desse esporte. Os movimentos dos atletas da modalidade são realizados em cima da plataforma/trampolim, no ar (quando o atleta está em queda livre) e na entrada na água. Tal especificidade altera os componentes físicos, biomecânicos e da técnica de execução desses movimentos, exigindo assim recursos específicos para o processo de aprendizagem e treinamento, tanto dentro como fora da piscina ${ }^{13,18,19}$.

Este estudo tem como mérito apresentar uma avaliação através da percepção dos principais treinadores de saltos ornamentais do Brasil sobre os recursos financeiros, como remuneração dos treinadores; materiais, como equipamentos de segurança para o treinamento dos saltos, trampolins para o treinamento dos atletas; e humanos, como comissão técnica especialista na modalidade, disponíveis atualmente para o processo de desenvolvimento de indivíduos que buscam alcançar o patamar de atletas olímpicos. Mesmo sendo um esporte olímpico, a modalidade vem sendo pouco investigada nacionalmente ${ }^{18} \mathrm{e}$ internacionalmente ${ }^{17}$ no meio acadêmico. Sendo assim, torna-se relevante apontar os problemas de forma científica que esse esporte enfrenta no Brasil com objetivo de acelerar o seu processo de desenvolvimento no âmbito prático e acadêmico. Somente com indicadores sobre os problemas relacionados à infraestrutura (recursos financeiros, materiais e humanos) será possível elaborar um planejamento estratégico de ações e de políticas públicas e privadas eficazes que aperfeiçoem o investimento feito na modalidade.

Posto isso, surgiu o questionamento: será que os treinadores têm recursos de excelência para desenvolver atletas olímpicos dos saltos ornamentais no Brasil? O objetivo do estudo foi analisar os recursos financeiros, materiais e humanos, através $\mathrm{da}$ percepção dos treinadores de saltos ornamentais, para o desenvolvimento de atletas olímpicos brasileiros. 


\section{Método}

O estudo apresenta uma abordagem qualitativa ${ }^{20}$. Tal abordagem permite uma visão holística acerca de um objeto ou processo ${ }^{21,22}$. Este tipo de estudo permite a compreensão de variáveis a partir da fala dos agentes que fazem parte integrante do ambiente no qual se pretende investigar ${ }^{23}$.

\section{Amostra}

Segundo levantamento realizado junto à Confederação Brasileira de Esportes Aquáticos ${ }^{24}$ existe no Brasil apenas sete treinadores que já trabalharam com atletas olímpicos de saltos ornamentais. Todos foram convidados a participar do estudo, entretanto somente seis treinadores $(85,71 \%)$ aceitaram participar. Os treinadores são do sexo masculino, possuem média de idade de $49,5 \pm 14,1$ anos e tempo de profissão em média de 28,5 $\pm 1,4$ anos. Três treinadores trabalham na região sudeste do Brasil, dois na região centro-oeste e um no nordeste. Todos trabalham com atletas de ambos os sexos.

Os critérios de inclusão para os treinadores que participaram do estudo foram: ter participado do desenvolvimento como treinador, em algum momento da carreira, de um atleta que disputou alguma edição dos Jogos Olímpicos na modalidade saltos ornamentais; estar trabalhando em um clube de saltos ornamentais no momento da coleta de dados. Já os critérios de exclusão são: treinar uma equipe que não seja filiada a Confederação Brasileira de Desportos Aquáticos ${ }^{24}$ e não ter experiência no desenvolvimento de atletas olímpicos.

$\mathrm{Na}$ apresentação dos resultados foi garantido a confidencialidade e o anonimato dos treinadores.

\section{Instrumentos}

\section{Questionário demográfico}

Os entrevistados preencheram um questionário demográfico a fim de estabelecer informações como idade, sexo, tempo e trajetória profissional (qual atleta olímpico de saltos ornamentais ele trabalhou e em que momento da carreira).

\section{Entrevista semiestruturada}

Foi utilizada a entrevista semiestruturada ${ }^{20,21}$ para verificar, através da percepção dos treinadores, se estes profissionais possuem recursos financeiros, materiais e humanos adequados e disponíveis para desenvolver atletas olímpicos de saltos ornamentais. $\mathrm{O}$ roteiro de entrevista foi validado por três experts doutores em Psicologia do Esporte ${ }^{25}$. O conteúdo do roteiro de entrevista foi baseado no estudo de CôTÉ et al. ${ }^{8}$ e em outros estudos que abordaram a temática recursos para o desenvolvimento de atletas ${ }^{6,7}$. Seguir um modelo teórico é recomendável pela literatura para a construção do roteiro da entrevista ${ }^{20,21}$.

$\mathrm{O}$ roteiro de entrevista apresentava três perguntas iniciais pré-estabelecidas:

1) Quais os recursos (financeiros, materiais e humanos) que você tem a disposição para treinar atletas olímpicos de saltos ornamentais?

2) Os recursos (financeiros, materiais e humanos) que tem são suficientes para o desenvolvimento de atletas olímpicos da modalidade?

3) Quando falta algum recurso para o desenvolvimento dos atletas, o que você faz para supri-lo?

A ordem das perguntas foi apresentada ao entrevistado de acordo com o andamento da entrevista, possibilitando ao pesquisador explorar de forma mais ampla o pensamento do entrevistado. Além disso, para uma compreensão mais holística sobre o tema, o entrevistador pode fazer novos questionamentos de acordo com a percepção do entrevistado ${ }^{20,22}$.

\section{Procedimentos}

Este estudo foi aprovado pelo Comitê de Ética em Pesquisa da Universidade Federal de Minas Gerais, sob protocolo número ETIC: 0502.0.203.000-10.

Em um primeiro momento os treinadores receberam uma carta convite explicando a natureza científica do estudo, seus objetivos, relevância e procedimentos metodológicos. Após a concordância dos treinadores em participar do estudo, foi agendando um horário para a realização das entrevistas que não atrapalhasse a rotina de treinamentos e competições. Os participantes do estudo assinaram um Termo de Consentimento Livre e Esclarecido. Os voluntários responderam um questionário demográfico antes da realização das entrevistas. A coleta de dados foi realizada por uma mesma pesquisadora (educadora física e ex-atleta da modalidade) em uma sala no local de trabalho ou na residência dos treinadores, de maneira que 
não houvesse qualquer tipo de interrupção. As entrevistas tiveram em média uma duração de aproximadamente quarenta e cinco minutos e foram registradas por meio de um gravador digital. Após as transcriçōes, as entrevistas foram enviadas aos treinadores. Estes profissionais assinaram um documento confirmando a veracidade dos dados e reencaminharam à pesquisadora responsável.

\section{Análise de dados}

Os conteúdos das entrevistas foram transcritos literalmente e enviados aos treinadores para a verificação da veracidade dos dados. Depois, os dados foram organizados utilizando-se a divisão dos textos em pequenas partes de informação, conhecidas como meaning units ou miniunidades (MUs), consideradas como partes do texto que contém uma ideia, episódio ou pedaço de informação por si só ${ }^{22,23}$.

As MUs foram subdivididas em categorias estabelecidas como representativas dos fatores investigados, de acordo com o modelo teórico referente aos recursos necessários para um atleta atingir um status de expert ${ }^{8}$. Na transcrição das falas dos treinadores foram geradas 97 MUs. Depois de apuradas as ideias representativas de cada MU, foram selecionadas 54 MUs que possuíam relação direta com o objetivo do estudo. Essas Mus foram classificadas em categorias e subcategorias por três experts (doutores em psicologia do esporte que possuem familiaridade com o método de entrevista utilizado no estudo) segundo o crivo de classificação por agrupamento de ideias ${ }^{20}$. Outros estudos, que investigaram a infraestrutura que atletas de elevado rendimento têm a disposição, usaram métodos semelhantes para analisar dados oriundos de entrevistas semiestruturadas ${ }^{6,7,8}$.

\section{Resultados}

A apresentação dos resultados foi realizada pelo tipo de recurso. As categorias das MUs foram separadas em: recursos financeiros, materiais e humanos. As MUs também foram subcategorizadas, de acordo com o conteúdo delas (FIGURA 1). Por questôes éticas, os nomes dos treinadores foram mantidos em sigilo e a representação deles foi feita pela letra T, numerados de 1 a 6 .

MUs: miniunidades

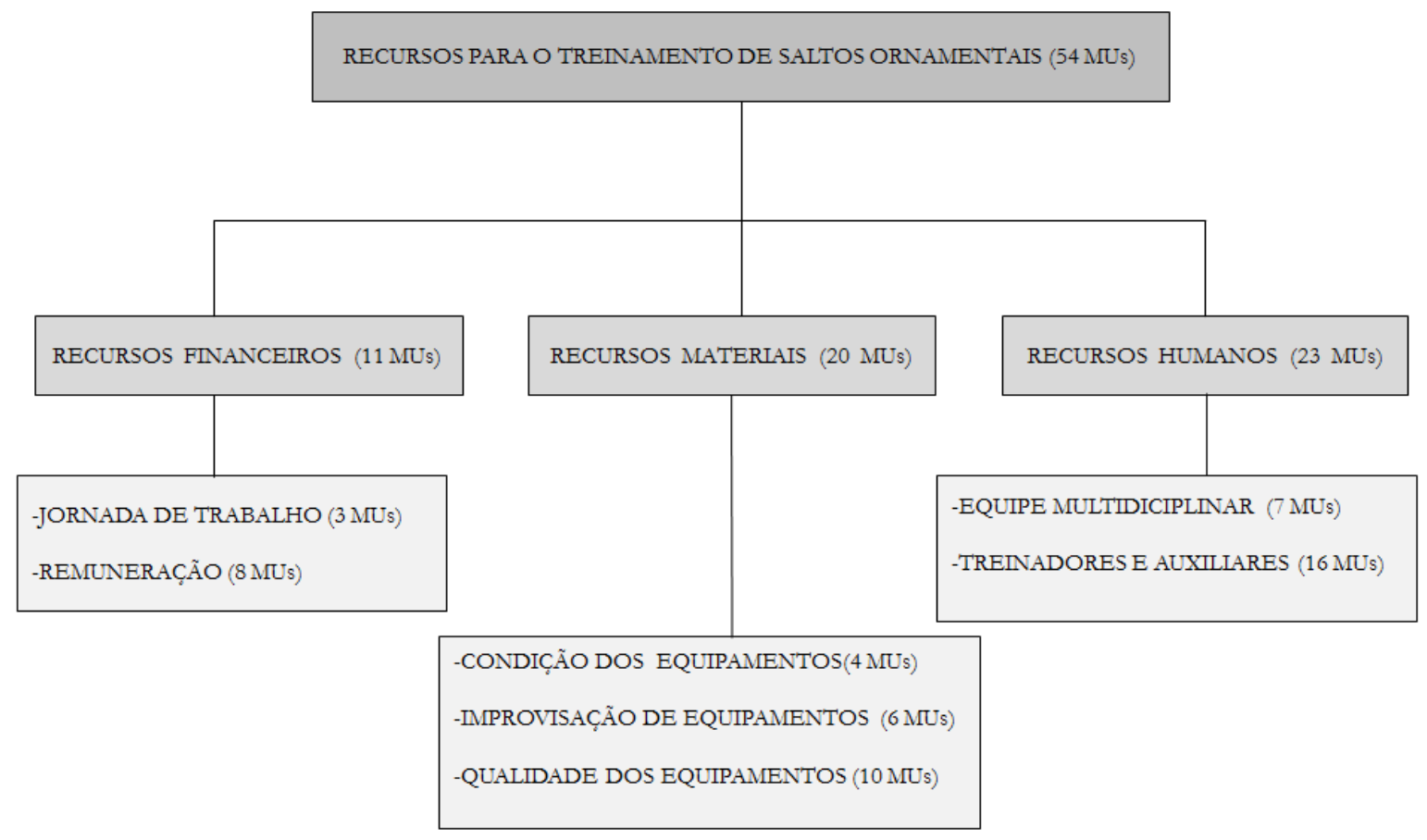

FIGURA 1 -Categorias formadas a partir da percepção dos treinadores sobre os recursos que ele tem à disposição para os treinamentos de saltos ornamentais. 


\section{Recursos Financeiros}

De acordo com a percepção dos treinadores avaliados, no geral, observa-se que estes profissionais apresentam problemas quanto aos recursos financeiros. $\mathrm{O}$ treinador $\mathrm{T} 3$ comentou sobre a falta de pagamento e que passou vários meses sem receber salário. T2 explica que possui uma longa jornada de trabalho e apenas um dia de folga.

[...] mas foi uma luta para mim aqui, eu passei 19 meses sem salário, isso aconteceu depois que o governador do Estado entrou em 2007, ele entrou para governador e tirou quase 20 mil cargos, [...] 19 meses trabalhando de graça aqui, [...] mas ninguém me tirou daqui, depois me devolveram o cargo e comecei a receber de novo (T3).

[...] eu trabalho em clube estritamente fechado, esse clube é de classe média alta, de poder aquisitivo elevado, você pode ver pela grandiosidade do clube, pelo tamanho do clube [...]. Eu chego aqui $8 \mathrm{~h}$ da manhã e não tenho hora para sair. Essa é a minha vida há mais de 40 anos. Estou aqui no clube há 36 anos, fora outros clubes que já estive. Trabalho de terça a domingo, só tenho a segundafeira de folga [...] (T2).

Já o treinador T6 explica que, na realidade brasileira, os treinadores de saltos ornamentais devem analisar antes de entrar na carreira se terão condiçôes financeiras para manter a família:

[...] ter uma estabilidade, [...] o técnico também tem que ter uma estrutura, de ter uma família que me apoia, e outra, se eu náo tenho uma condição financeira como é que eu vou sair e manter a minha mulher lá, é complicado [...] (T6).

Ao analisar as MUs das entrevistas com os treinadores observa-se que a frequência dos problemas apresentados no bloco de recursos financeiros está centralizada em dois aspectos primordiais: baixa remuneração pela atividade laboral desempenhada $\mathrm{e}$ a jornada de trabalho elevada, com muitas horas de trabalho e poucos períodos de descanso, em especial nos finais de semana.

\section{Recursos Materiais}

A metade dos treinadores comentou sobre a escassez de bons equipamentos. $\mathrm{O}$ treinador $\mathrm{T} 5$ relatou como faz para suprir a falta de material como cinto de segurança, usado para simular os saltos fora da piscina e proporcionar segurança aos atletas na hora de realizar o salto na água. Tal situação, conforme menciona $\mathrm{T} 5$, prejudica o trabalho dos treinadores junto aos atletas.

[...] aqui no caso que nós não temos cinto, suprimos esta falta com trabalho mais paulatinamente, esmiuçado, feito em partes, trabalho externo à piscina [...] até construir o todo, divido as coisas uma por uma, no que chamamos de esporte de processo. Isso atrapalha muito o trabalho [...] $\mathrm{O}$ trabalho de precisão é feito com cinto de segurança, como não temos o cinto, treino parte por parte os elementos esmiuçando o treinamento (T5).

Já o T3 explicou que seus equipamentos não são oficiais e que levou muito tempo para conseguí-los:

É, eu tenho praticamente tudo [...] apesar de ser improvisado, [...], esse ano foi que eu comprei sete trampolins novos, então eu levei 7 anos para comprar, depois que comprei já tem 2, 3 anos que esses trampolins estão aí [...] (T3).

O treinador T1 falou da desvantagem de ter um ginásio a céu aberto, o que atrapalha a rotina de treinamento com os atletas. Os atletas treinados por T1 são prejudicados na preparação nos períodos de chuva:

Hoje nós temos um centro bom, temos um ginásio com cama elástica, o cinto de segurança para simulação dos saltos fora da água, temos o trampolim fora da água com colchão e o cinto de segurança, na piscina temos dois trampolins de $3 \mathrm{~m}$ e 3 trampolins de $1 \mathrm{~m}$ [...] No Rio tem um belo de um ginásio de preparação, Brasília também, Campinas também tem um belo de um saláo com cama elástica, a nossa desvantagem é que choveu, não dá pra usar mais aquilo lá, temos que ir para ginástica olímpica, mas nem sempre de manhã nós podemos, essa é a nossa desvantagem (T1).

Já os treinadores $\mathrm{T} 4 \mathrm{e} \mathrm{T} 6$ relataram outra realidade, com melhores recursos materiais para o treinamento dos atletas. T6 relatou uma série de recursos materiais que auxiliam no desenvolvimento dos atletas:

Praticamente tem tudo, pouca coisa que falta, mas 
nada que prejudique ou que atrapalhe, falando de estrutura física, isso porque eu tenho uma equipe pequena [...] (T4).

[...] essa é uma estrutura boa, eu tenho um ginásio [...] você tem que ter ginásio com cama elástica, cinto de segurança é muito importante, o trampolim, e sabendo o que você vai trabalhar, sabendo qual é o objetivo [...] é muito importante também ter bons trampolins, o trampolim velho não responde [...] um bom clima externo e de água [...]. Então isso é o material que nós estamos tendo, e o mais importante de tudo isso, até na formação, são cintos de segurança na água [...]. Novo recurso para auxiliar no treinamento câmera filmadora - que torna possível ver o salto junto com o atleta. Além disso, pode-se jogar no gráfico para fazer análise técnica de toda a passada do salto e traçar marcas técnicas [...] (T6).

Em síntese, pode-se observar que existe uma carência de recursos materiais em $66 \%$ da amostra estudada. Tal situação passa pela carência de um ginásio coberto para treinamento, escassez de aparelhos oficiais e até mesmo ausência de aparelhos de segurança. Os treinadores que relatam possuir equipamentos de qualidade para o treinamento representam uma exceção no quadro de desenvolvimento de atletas de elevado rendimento de saltos ornamentais e de outras modalidades olímpicas no Brasil.

\section{Recursos Humanos}

Os treinadores entrevistados, exceto T6, consideram que a maior carência para o desenvolvimento dos atletas olímpicos de saltos ornamentais refere-se aos recursos humanos disponibilizados pelos clubes. Tais treinadores comentaram sobre a falta de uma equipe multidisciplinar para auxiliar na rotina de treinamentos e competiçôes:

Me faz muita falta e eu garanto para você que é praticamente impossível cuidar sozinho de um trabalho que você pensa no alto rendimento. Trabalhar sozinho é o que mais me atrapalha no meu trabalho [...] me faz muita falta sim, porém, é muito difícil encontrar uma pessoa hoje adequada, que queira entrar na profissão de treinador. Também é difícil ter recurso para contratar uma equipe multidisciplinar (T2).
Tenho um monitor que está me ajudando na escolinha, eu dou o treinamento aqui em baixo e ele está dando a escolinha lá em cima, [...] a parte física eu tenho, mas eu precisava conseguir dividir os treinamentos, teria que ter mais gente para trabalhar com a parte física. Tinha que ter uma programação mais separada, o pessoal novo treina junto com o pessoal velho. Não era para ser assim, teria que ter um treinamento a mais, com mais profissionais para ajudar no processo [...] (T3).

O treinador T4 deixou claro que a falta de profissionais é o aspecto que mais impacta no desenvolvimento dos atletas. Um auxiliar técnico, por exemplo, poderia ajudar os treinadores na execução do programa de treinamentos:

Eu tenho os meus atletas aqui, aí eu viajo com eles boa parte do ano, e eu preciso de alguém para continuar os treinos com os outros atletas que ficam aqui e de ter uma base [...] agora mesmo eu trouxe uma auxiliar técnica de São Paulo, para estar aqui, então, falta profissionais em todo lugar. A falta de profissionais para me ajudar é o que mais me atrapalha para treinar meus atletas. Fica muito difícil trabalhar assim (T4).

Apenas o treinador T6 relatou que tinha uma equipe multidisciplinar para o treinamento dos atletas de saltos ornamentais:

Hoje, por exemplo, no trabalho com nosso melhor atleta brasileiro, eu não estou sozinho, eu tenho uma equipe multidisciplinar comigo $[. .$.$] , eu tenho um preparador$ físico fantástico, eu tenho um psicólogo, uma nutricionista, um massagista e tenho um estatístico, que me dá números sobre o desempenho dos atletas [...], tenho um auxiliar técnico também (T6).

De acordo com a percepção dos treinadores fica evidente que a carência de recursos humanos afeta diretamente o trabalho destes profissionais. A preparação dos atletas, visando o ápice de rendimento em competições internacionais, requer uma equipe multidisciplinar composta por preparador físico, fisioterapeuta, auxiliar técnico, médico, psicólogo do esporte, entre outros. Tais profissionais, de acordo com os treinadores entrevistados, complementaria o trabalho com os atletas, além de aliviar a sobrecarga de funções dos entrevistados. 


\section{Discussão}

O objetivo do estudo foi analisar os recursos financeiros, materiais e humanos, através da percepção dos treinadores de saltos ornamentais, para o desenvolvimento de atletas olímpicos brasileiros. Pode-se dizer que a base para desenvolver atletas experts, além da prática deliberada, é o acesso destes indivíduos aos recursos financeiros, materiais e humanos de alta qualidade. Tal contexto não só otimiza o treinamento como também traz uma condição satisfatória de trabalho aos atores envolvidos no processo ${ }^{4,7}$. Posto isto, será discutido cada um dos tipos de recursos relacionados ao treinamento de atletas dos saltos ornamentais brasileiro.

Os recursos financeiros são um dos pilares que dão suporte ao desenvolvimento dos atletas de alto rendimento ${ }^{6,7,10}$. Porém, no geral, os treinadores entrevistados apresentaram problemas financeiros para formar atletas olímpicos de saltos ornamentais. Tais profissionais reclamaram principalmente dos baixos salários, do atraso ou falta de pagamento dos vencimentos, além de longas jornadas de trabalho.

O suporte financeiro ao esporte no Brasil é destinado a alguns poucos programas voltados ao esporte de alto rendimento, atendendo a um número reduzido de atletas ${ }^{11}$. Percebe-se que houve investimentos em infraestrutura voltados principalmente para a realização de grandes eventos, como foi no Pan Rio/2007, na Copa do Mundo de Futebol em 2014 e nos Jogos Olímpicos do Rio de Janeiro em 2016. Porém existem poucas rubricas de recursos destinadas à melhoria $\mathrm{e}$ qualificação dos treinadores que trabalham com o desenvolvimento de atletas olímpicos brasileiros ${ }^{11}$. Somente qualificando a formação técnica dos treinadores e proporcionando a eles conteúdo técnico-científico de qualidade sobre a modalidade será possível o desenvolvimento sistemático de atletas com potencial de disputar Jogos Olímpicos.

Além disso, MeIra, BAstos e BöHME ${ }^{26}$ ressaltam que os recursos provenientes das loterias federais e dos patrocínios de empresas estatais, como Correios e Petrobras, não são destinados para a melhoria das condições de trabalho e qualificação dos treinadores, como no caso dos profissionais dos saltos ornamentais que desenvolvem atletas olímpicos ${ }^{26}$.

Estudos realizados com atletas brasileiros relatam problemas semelhantes no que tange a falta de apoio do governo e de vários setores da iniciativa privada no que tange a escassez de recursos financeiros para os esportes olímpicos mostram que outros esportes também apresentam uma carência referente aos recursos financeiros ${ }^{6,7,15}$. REIs et al. ${ }^{7}$ relataram problemas com a falta de recursos financeiros para o desenvolvimento de atletas de basquetebol de Minas Gerais. A maior parte dos atletas não tem à disposição salários, auxílio financeiro (bolsa) e transporte para treinar e competir. Já Ferreira et al. ${ }^{6}$ ao estudarem a trajetória esportiva de atletas brasileiros medalhistas olímpicos de natação verificaram que estes indivíduos precisavam migrar para os Estados Unidos em busca de melhores patrocínios e bolsas de estudos e condições para treinamento e competição. Uma investigação com treinadores de alto rendimento de natação e judô constatou, a partir da percepção desses profissionais, que não existe no Brasil um sistema nacional, financiado pelo governo, para o desenvolvimento de atletas de alto rendimento ${ }^{15}$. Esse número de evidências de estudos envolvendo diferentes modalidades olímpicas no Brasil retrata um cenário desolador, com um denominador em comum: a falta de recursos financeiros para promover e desenvolver o esporte na sociedade em geral e também para o desenvolvimento de novos atletas no país.

Cada modalidade esportiva tem suas peculiaridades e sua própria demanda de equipamentos e materiais, sendo esse um pilar importante no processo de formação de novos atletas ${ }^{9}$. Sem recursos materiais de qualidade, como por exemplo, um bom trampolim de saltos, o atleta sempre estará aquém de desempenhar todo o seu potencial. Os recursos materiais dão suporte às rotinas de treinamento, sendo que equipamentos de qualidade podem acelerar e até maximizar o desempenho dos atletas ${ }^{4,7,8}$. Equipamentos de má qualidade ou em mau estado de conservação podem provocar acidentes e lesões aos atletas ${ }^{12}$.

A realidade apresentada pelos treinadores de saltos ornamentais deste estudo mostra que metade deles possuem equipamentos improvisados e locais inapropriados para o treinamento de seus atletas, até mesmo carência de equipamentos. Os resultados do estudo apontam que a maior parte dos treinadores precisam se adaptar à realidade de déficit material, e realizam também uma série de improvisaçōes para desenvolver os atletas olímpicos. Como consequência deste cenário, o Brasil não 
tem conseguido preparar adequadamente atletas dos saltos ornamentais para uma equipe olímpica, o que culmina em resultados inexpressivos em competiçōes internacionais ${ }^{16}$.

Resultados semelhantes, quanto aos recursos materiais, podem ser encontrados no estudo de Ferreira et al. ${ }^{6}$ com nadadores medalhistas olímpicos brasileiros. Tal trabalho mostrou que, muitos destes atletas não estavam satisfeitos com as condições materiais que tinham à disposição no Brasil e por isso, se mudaram para os Estados Unidos em busca de melhores condiçôes estruturais de treinamento que permitissem desenvolver todo o potencial atlético deles.

Existem poucas "ilhas" de excelência esportiva no Brasil. Um exemplo que ilustra uma realidade diferente da exposta pelos treinadores entrevistados refere-se à estrutura do Centro de Treinamento de Ginástica Artística construído no Paraná, sul do Brasil ${ }^{13}$. O centro contém equipamentos de ponta, treinadores considerados experts e equipe multidisciplinar qualificada, além disso, as melhores atletas do Brasil na modalidade se concentram neste mesmo local para se prepararem para competições de alto nível. O resultado disso é a melhora dos resultados no quadro de medalhas brasileiras na ginástica artística nos últimos Jogos Pan Americanos, Mundiais e Jogos Olímpicos ${ }^{27,28}$.

Estes resultados da ginástica demonstraram que o contexto de treinamento faz diferença quando se trata de alto nível. Como pôde ser visto nos Jogos Olímpicos do Rio de Janeiro em 2016 ${ }^{16}$, os resultados de atletas brasileiros nos saltos ornamentais ainda podem ser considerados abaixo da crítica quando comparado a países como a China. Este país há 30 anos apresenta os melhores resultados na modalidade em jogos olímpicos e campeonatos mundiais. $\mathrm{Na}$ China existe um contingente de milhares de atletas espalhados por dezenas de centros olímpicos muito bem equipados e com profissionais altamente qualificados ${ }^{29}$.

SCHiAvon e PAEs ${ }^{12}$ também ressaltam a importância de um centro de treinamento que visa à preparação de atletas de alto desempenho, afirmam que é fundamental ter em suas instalações equipamentos que seguem padrões internacionais de qualidade. Este estudo ${ }^{12}$, investigou as condiçốes de treinamento de ginastas olímpicas brasileiras, do sexo feminino, entre o período de 1980 a 2004. Constatou-se que de 1999 a 2008 foi o período que as atletas mais se desenvolveram, pois foi proporcionado a essas atletas recursos como: moradia, dois ginásios com aparelhos oficiais e auxiliares completos, treinadores internacionalmente qualificados e equipe multidisciplinar. Mesmo assim, as atletas beneficiadas com o Centro de Treinamento já treinaram em algum momento da carreira em ambientes precários quanto à infraestrutura.

Quanto aos recursos humanos, o déficit de uma equipe multidisciplinar, segundo a percepção dos treinadores, é a variável que mais afeta o desenvolvimento dos atletas. A queixa mais frequente foi a carência de profissionais qualificados, principalmente de treinadores e auxiliares técnicos que tenham conhecimentos suficientes para ajudar no desenvolvimento e treinamento dos atletas. Uma equipe multidisciplinar é crucial para o desenvolvimento de atletas de alto rendimento. $\mathrm{O}$ treinador, sozinho, não é capaz de atender todas as demandas que o atleta de alto rendimento necessita para desenvolver todo o seu potencial ${ }^{6,7,8}$.

FERREIRA et al. ${ }^{6}$ também relataram as dificuldades que nadadores medalhistas olímpicos brasileiros tiveram durante a carreira pela carência de profissionais especializados no Brasil. Os atletas que tinham uma equipe multidisciplinar completa são aqueles que foram para os Estados Unidos em busca de melhores condições, muitos que persistiram no Brasil, tinham apenas o treinador, um auxiliar técnico e um médico a disposição para acompanhar os treinamentos. ReIs et al. ${ }^{7}$ também apontaram que a maioria dos atletas das categorias de base do basquetebol de Minas Gerais não têm acesso a recursos humanos, como preparador físico, auxiliar técnico,fisioterapeuta, nutricionista, médico e psicólogo. Um trabalho que investigou o contexto do desenvolvimento de atletas de ginástica artística no estado de São Paulo mostrou que o número de treinadores é considerado baixo para a demanda de atletas, além disso, a maior parte das instituições não apresenta uma comissão técnica completa ${ }^{14}$.

Contrapondo este cenário, Nunomura e Oliverra ${ }^{13}$ verificaram que, no centro de treinamento de excelência de ginástica artística, sediado em Curitiba (PR/Brasil), as atletas têm à disposição uma equipe multidisciplinar composta por: médicos, fisioterapeutas, psicólogos, nutricionistas, coreógrafos e coordenadores que gerenciam as demandas das seleções permanentes. De acordo com as autoras, o conceito de seleção permanente iniciou-se com a chegada de treinadores estrangeiros experts com experiência em desenvolver 
atletas medalhistas em campeonatos mundiais e jogos olímpicos.

Conclui-se, a partir deste estudo, que existe no contexto brasileiro uma precariedade de recursos financeiros, materiais e humanos para o desenvolvimento de atletas de saltos ornamentais com potencial para atingir o patamar de atleta olímpico. $\mathrm{Na}$ percepção dos treinadores há um distanciamento entre os recursos existentes e aqueles necessários para a implantação de um processo sistematizado de desenvolvimento de atletas de elevado rendimento. Pode-se observar também, a partir deste contexto, que clubes e das entidades que comandam os saltos ornamentais no Brasil investem pouco no sentido de fomentar a infraestrutura condizente à prática do esporte de excelência.

O trabalho foi o pioneiro em verificar a atual estrutura de treinamento que treinadores brasileiros têm à disposição para o desenvolvimento dos atletas olímpicos de saltos ornamentais. Neste presente estudo observou-se que os recursos financeiros, materiais e humanos para os saltos ornamentais no Brasil ainda são insuficientes para o desenvolvimento de atletas olímpicos Pode-se considerar como limitação deste estudo, o fato de ter sido feito a análise dos recursos financeiros, materiais e humanos que os treinadores dos saltos ornamentais brasileiros têm à disposição apenas pela percepção e pelo relato destes profissionais. Não foi possível confrontar os dados a partir da percepção de outros agentes importantes dentro do processo de desenvolvimento de atletas brasileiros olímpicos dos saltos ornamentais, como pais dos atletas, dirigentes e os próprios atletas em questão. Além disso, o resultado do presente estudo não pode ser extrapolado para outras realidades dos saltos ornamentais, já que o contexto que a população que participou do estudo, treinadores que desenvolvem atletas olímpicos, é considerado restrito e particular.

As discussões sobre os recursos financeiros, materiais e humanos contribuem para a compreensão dos fatores contextuais para que dirigentes, gestores esportivos e treinadores e outros profissionais que trabalham com a modalidade de saltos ornamentais tomem ciência da realidade do esporte no país e possam buscar alternativas dentro do ambiente esportivo para modificar a situação atual. É necessário também que sejam criadas políticas públicas que proporcionem recursos de excelência para o desenvolvimento de jovens atletas de saltos ornamentais. As entidades que desenvolvem atletas da modalidade poderiam também traçar melhores estratégias para se beneficiar de recursos financeiros provenientes das leis de incentivo ao esporte, tanto na esfera federal como na estadual.

Propõe-se que outros estudos sejam realizados com o objetivo de analisar a percepção de outros agentes que militam no esporte, como dirigentes e os próprios atletas. Tais investigaçōes contribuirão para um melhor entendimento sobre o contexto de desenvolvimento de atletas brasileiros de excelência de saltos ornamentais.

\section{Abstract}

Financial, Material and Human Resources for the Development of Brazilian Diving Olympic Athletes

The aim of the study was to analyze the financial, material and human resources for the development of Brazilian Olympic athletes, through the perception of diving coaches. The sample consisted of six diving coaches, with an average age of 49,5 $\pm 14,1$ years, who have trained Olympic athletes in Brazil. Semi-structured interviews were conducted with the coaches. The content of the interviews was transcribed literally, and then analyzed through meaning-units (MUs). The MUs were organized into three categories. Both the content of the interviews and the categorization of the MUs were reviewed by experts. As for the financial resources, the coaches reported that they have low salaries and a long working day. Three interviewees stressed the lack or precariousness of material resources. Most of the coaches do not have a multidisciplinary team to develop athletes, the lack of human resources being the most disruptive factor in their work. It is concluded that diving in Brazil exhibits a deficient structure regarding the financial, material and human resources for the development of Olympic athletes.

KEYwords: Physical Education and Training; Water Sports; Infrastructure; High Performance Sports. 


\section{Referências}

1. Ericsson KA, Krampe RT, Tesch-Römer C. The role of deliberate practice in the acquisition of expert performance. Psychol Rev. 1993;100(3):363-406.

2. Ericsson KA, Lehmann AC. Expert and Exceptional Performance: Evidence of maximal Adaptation to task constraints. Annu Rev Psychol. 1996;47:273-305.

3. Ericsson KA. Deliberate practice and acquisition and maintenance of expert performance: in medicine and related domains. Acad Med. 2004;79(10):70-79. doi:10.1111/j.1553-2712.2008.00227.x.

4. Ericsson KA. How to gain the benefits of the expert performance approach in domains where the correctness of decisions are not readily available: a reply to weiss and shanteau. Appl Cogn Psychol. 2014;28(4):458-463. doi: 10.1002/ acp.3029.

5. Ward P, Hodges NJ, Starkes JL, Williams AM. The road to excellence: deliberate practice and the development of expertise. High Abil Stud. 2007;18(2):119-153. doi:10.1080/13598130701709715.

6. Ferreira RM, Penna EM, Costa VT, Moraes LC. Nadadores medalhistas olímpicos: contexto de desenvolvimento brasileiro. Motriz. 2012;18(1):130-142.

7. Reis CP, Moraes LC, Ferreira MC, Noce F, Costa VT. Recursos humanos, financeiros e materiais de atletas de basquetebol nas categorias de base e a percepção dos treinadores sobre a formação dos atletas. Rev Bras Edc Fís Esporte. 2014;28(3):491-503. doi: 10.1590/1807-55092014000300491.

8. Côté J, Salmela J, Trudel P, Baria A, Russel S. The coaching model: a grounded assessment of expert gymnastic coaches knowledge. J Sport Exerc Psychol. 1995;17(1):1-17. doi: 10.1123/jsep.17.1.1.

9. Moraes LC, Salmela JH. Expertise no esporte: consideraçóes contextuais. In: Garcia ES, Lemos KL, editores. Temas atuais VII: Educação Física e Esportes. Belo Horizonte: Health; 2003. p. 159-172.

10. De Bosscher V, Knop P, Bottenburg MV, Shibli S, Bingham J. Explaining international sporting success: an international comparison of elite sport systems and policies in six countries. Sport Manage Rev. 2009;12(3):113-136. doi:10.1016/j. smr.2009.01.001.

11. Athayde P, Mascarenhas F, Salvador E. Primeiras aproximações de uma análise do financiamento da política nacional de esporte e lazer no Governo Lula. Rev Bras Ciênc Esporte. 2015;37(1):2-10. doi: 10.1016/j.rbce.2013.09.0020.

12. Schiavon LM, Paes RR. Condiçóes dos treinamentos de ginastas brasileiras participantes de jogos olímpicos (19802004). Motriz. 2012;18(7):57-69.

13. Nunomura M, Oliveira MS. Centro de excelência e ginástica artística feminina: a perspectiva dos técnicos brasileiros. Motriz. 2012;18(2):378-392.

14. Lima LB, Murbach MA, Ferreira MD, Schiavon LM. Análise das condições de desenvolvimento da ginástica artística no Estado de São Paulo. Rev Bras Educ Fís Esporte. 2016;30(1):133-143. doi:10.1590/1807-55092016000100133.

15. Silva Filho FJ, Meira TB, Mazzei LC, Bastos FC, Böhme MT. Talentos esportivos no judô e na nataçáo. Rev Bras Educ Fís Esporte. 2016;30(3):627-36.

16. FINA. Fédération Internacionale de Natation. Diving World Rankings [Internet]. Switzerland: FINA; 2016 [cited 2016 aug 10]. Available from: http://www.fina.org/H2O/index.php?option=com_content\&view=article\&id=904\&I temid=570.

17. Reed CL. Chronometric comparisons of imagery to action visualizing versus physically performing spring board dives. Psychonomy Society. 2002;30:1169-1179.

18. Barris SS, Farrow D, Davids K. Do the kinematics of a baulked take-off in springboard diving differ from those of a completed dive. J Sport Sci. 2013;31(3):305-313. doi: 10.1080/02640414.2012.733018.

19. Vieira S, Freitas A. O que é a natação sincronizada e saltos ornamentais: história, regras e curiosidades. Rio de Janeiro: Casa da Palavra; 2006.

20. Patton MQ. Qualitative research \& evaluation methods: integrating theory and practice. 4a ed. Thousand Oaks: Sage; 2015.

21. Engel RJ, Schutt RK. Survey research. In: Grinnell U, editor. Social work research and evaluation foundations of evidence-base practice. Oxford: Oxford University Press; 2011. p. 326-364.

22. Gratton C, Jones I. Research methods for sport studies. 2a ed. London: Routledge; 2010.

23. Fraser MT, Gondim SM. Da fala do outro ao texto negociado: discussóes sobre entrevistas qualitativas. Paidéia. 2004;14:139-152. doi: 10.1590/S0103-863X2004000200004.

24. CBDA. Confederação Brasileira de Desportos Aquáticos. Resultados. Rio de Janeiro: CBDA; 2010 [citado 11 ago 
2016]. Disponível em: http://www.cbda.org.br/saltosornamentais/resultados.htm.

25. Côté J, Ericsson KA, Law MP. Tracing the development of athletes using retrospective interview methods: a proposed interview and validation procedure for reported information. J Appl Sports Psychol. 2005;17(1):1-19. doi: 10.1080/10413200590907531.

26. Meira TB, Bastos FC, Böhme MT. Análise da estrutura organizacional do esporte de rendimento no Brasil: um estudo preliminar. Rev Bras Educ Fís Esporte. 2012;26(2):251-62.

27. CBG. Confedração Brasileira de Ginástica. São Paulo: CBG; 2016 [citado 10 ago 2016]. Disponível em: http://www. cbginastica.com.br.

28. FIG. Fédération Internationale de Gymnastique. Switzerland: FIG; 2016 [citado 10 ago 2016]. Disponível em: http:// www.fig-gymnastics.com/event/index.php.

29. CSA. Chinese Swimming Association. Beijing: CSA; 2016 [citado 10 ago 2016]. Disponível em: http://en.olympic. cn/sports/summer_sports/2003-12-04/24274.html.

ENDEREÇO DE CORRESPONDÊNCIA:
Varley Teoldo Costa
Av. Carlos Luz, 4664

Belo Horizonte - MG - BRASIL

CEP: 31140120

E-mail: vtcosta@hotmail.com

Submetido: 26/09/2017

$1^{\mathrm{a}}$ revisão: $25 / 12 / 2017$

$2^{\mathrm{a}}$ revisão: $14 / 03 / 2018$

Aceito: 09/04/2018 